\title{
POTENCIALIDADES DO RECURSO DA ÁUDIO-DESCRIÇÃO PARA O TRANSPORTE E PARA OS ESPAÇOS PÚBLICOS URBANOS
}

\author{
SILVEIRA, Carolina Stolf (1) \\ (1) Universidade Federal de Santa Catarina, Doutora em Arquitetura e Urbanismo \\ e-mail: carolinastolf@gmail.com
}

DISCHINGER, Marta (2)

(1) Universidade Federal de Santa Catarina, Ph.D., Orientadora

e-mail: martadischinger@gmail.com

\begin{abstract}
RESUMO
Um dos grandes desafios das cidades na atualidade é conciliar a oferta de espaços públicos acessíveis e inclusivos com os escassos recursos financeiros dos municípios brasileiros. Os meios públicos de transporte, principalmente por ônibus no Brasil, comumente apresentam pouca ou nenhuma informação sobre estações, itinerários e horários aos usuários, especialmente informação não visual para aqueles que não podem enxergar. No espaço público urbano, pessoas com cegueira ou baixa visão são privadas de usufruir de determinados espaços quando esses são projetados desconsiderando aqueles que não podem enxergar. Este artigo apresenta exemplos de como a áudio-descrição pode fortemente auxiliar pessoas com cegueira e baixa visão no transporte coletivo e também em espaços públicos urbanos, com a apresentação de dois exemplos europeus (Londres e Viena) e de um projeto piloto desenvolvido pela autora em sua cidade natal, mostrando como a áudiodescrição pôde tornar o Mirante da cidade de Joinville, Santa Catarina, em um espaço inclusivo para quem não pode contemplar a paisagem com os olhos.
\end{abstract}

Palavras chave: áudio-descrição; pessoas com deficiência visual; espaços públicos urbanos.

\begin{abstract}
One of the major challenges facing cities nowadays is to reconcile the offer of accessible and inclusive public spaces with the scarce financial resources of Brazilian municipalities. Public transport means, mainly by bus in Brazil, usually have little or no information about stations, itineraries and schedules for users, especially non-visual information for those who can not see. In the urban public space, people with blindness or low vision are deprived of enjoying certain spaces when they are projected disregarding those who can not see. This article presents examples of how audio description can strongly assist blind people in public transport and also in urban public spaces, with the presentation of European examples (London and Wien) and a pilot project developed by the author at your home town showing how the audio description could make the Viewpoint of the city of Joinville, Santa Catarina, Brazil, in an inclusive space for those who can not contemplate the landscape with their eyes.
\end{abstract}

Keywords: audio description; people with visual impairment; urban public spaces.

\section{INTRODUÇÃO}

A Lei Brasileira de Inclusão (BRASIL, 2015) assegura e promove condições de igualdade, exercício dos direitos e liberdades fundamentais, visando a inclusão social e a cidadania da pessoa com deficiência. Dentre outros, apresenta as diretrizes do desenho universal e a promoção de espaços acessíveis para todas as pessoas, independente de suas condições físicas ou sensoriais, que devem ser atendidas por arquitetos, urbanistas, paisagistas, 


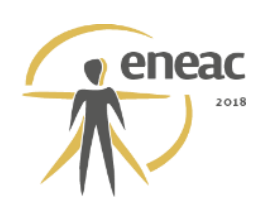

designers, engenheiros, e demais profissionais envolvidos como o ato de projetar e executar espaços, objetos, mobiliários, equipamentos e serviços para a utilização das pessoas.

Dentre os princípios da Convenção sobre os Direitos das Pessoas com Deficiência (BRASIL, 2014) está o de Igualdade de Oportunidades. Esse princípio define que o sistema geral da sociedade - meio físico e cultural, moradia e transporte, serviço social e de saúde, oportunidades de educação e de trabalho, vida cultural e social inclusive instalações desportivas e de lazer - deve ser acessível a todos.

Um dos desafios das cidades na atualidade é garantir e efetivar esse princípio nos diversos espaços públicos urbanos, considerando que por vezes faltam recursos financeiros, corpo técnico ou mesmo vontade política para colocá-lo em prática através do desenho universal e recursos de acessibilidade disponíveis.

A Lei Federal no 12.587/12, que institui as diretrizes da Política Nacional de Mobilidade Urbana, no capítulo III, sobre os direitos dos usuários, tem determinado em seu Artigo 14, dentre outros, que o usuário tem o direito de: "ser informado nos pontos de embarque e desembarque de passageiros, de forma gratuita e acessível, sobre itinerários, horários, tarifas dos serviços e modos de interação com outros modais". Apesar disso, o componente informação ao usuário é escasso e muitas vezes inexistente nos sistemas urbanos de transporte público coletivo brasileiros, especialmente no que diz respeito prover informação para todos, visto que, quando as poucas informações aparecem são apenas de forma visual.

Assim, o presente artigo busca apresentar alguns exemplos de como a áudio-descrição pode ser uma importante técnica com baixo ou nenhum custo financeiro para incluir e oferecer acessibilidade às pessoas com deficiência visual no meio de transporte e em espaços públicos urbanos.

Os exemplos aplicados aos sistemas de transporte trazidos para divulgação através do presente artigo foram encontrados durante o estágio de doutorado sanduíche na Europa em que a autora pôde avaliar os sistemas de transporte coletivo de Bruxelas, Londres e Viena, sendo que nos dois últimos a áudio-descrição foi utilizada para orientar e oferecer independência às pessoas com cegueira e baixa visão usuárias desses sistemas.

O exemplo que se aplica aos espaços públicos urbanos, refere-se a um projeto piloto desenvolvido pela autora mediante a função de trabalho desempenhada durante certo período na Fundação Instituto de Pesquisa e Planejamento para o Desenvolvimento Sustentável de Joinville/SC (Fundação IPPUJ) e a partir dos estudos realizados no doutorado (Silveira, 2017 - orientada por Marta Dischinger), o qual envolveu mais de 200 pessoas com cegueira e baixa visão residentes em diversas regiões do Brasil, através da coleta de informações por questionários, entrevistas, passeios acompanhados e grupo focal online, abordando temas de orientação e mobilidade, áudio-descrição, pisos e mapas táteis, dentre outros.

\section{A PESSOA COM DEFICIÊNCIA VISUAL E A ÁUDIO-DESCRIÇÃO}

De acordo com a Classificação Internacional de Doenças (OMS, 2006), a função visual é dividida em quatro níveis: visão normal; deficiência visual moderada; deficiência visual grave; e cegueira.

A deficiência visual moderada e grave são comumente agrupadas sob o termo "baixa visão". Baixa visão é a perda severa da visão com vários graus de visão residual. A capacidade funcional da visão é reduzida decorrente de inúmeros fatores isolados ou associados, tais como baixa acuidade visual, redução importante do campo visual, alterações corticais e/ou de sensibilidade aos contrastes, que interferem ou que limitam o desempenho visual do indivíduo. 


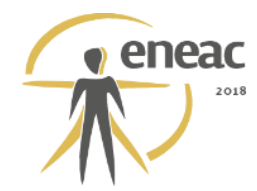

A cegueira total pressupõe completa perda de visão. A visão é nula, isto é, nem a percepção luminosa está presente. Com cegueira parcial, o indivíduo é capaz de identificar a direção de onde provém luz (distinguir claridade e escuridão).

Segundo dados do Censo de 2010 do Instituto Brasileiro de Geografia e Estatística (IBGE, 2010), dentre os 190.755.799 de habitantes no Brasil, 35.774.392 de pessoas declararam ter deficiência visual (incapacidade visual, mesmo com o uso de lentes), dessas, 29.211.482 afirmaram que tinham alguma dificuldade de enxergar, 6.056.533 disseram ter grande dificuldade (baixa visão) e 506.377 informaram que não conseguem enxergar de modo algum (cegueira).

Os sentidos remanescentes de pessoas com cegueira envolvem as percepções não visuais, através da audição (sistema auditivo), o tato (sistema háptico, principalmente o tato ativo), o olfato (sistema olfato-paladar), a cinestesia, a memória muscular e o sentido vestibular, compondo o sistema básico de orientação da teoria desenvolvida James Gibson (GIBSON, 1966), psicologista americano, Ph.D. no campo da percepção. Para pessoas com baixa visão o aproveitamento máximo de qualquer grau de visão é utilizado para sua orientação e mobilidade.

Além das técnicas de orientação e mobilidade, comumente ensinadas nas instituições de ensino e apoio às pessoas com deficiência visual para que possam aprender a orientar-se e deslocar-se de maneira independente, segura e eficiente, tais como as técnicas do guia vidente, da auto-proteção, da bengala e do cão guia, existem diversos recursos de acessibilidade para pessoas com deficiência visual, tais como leitores de tela, braille, mapas e maquetes táteis, e a áudio-descrição.

A áudio-descrição consiste na descrição clara e objetiva de todas as informações que compreendemos visualmente. Na definição de Livia Motta, doutora em linguística e áudiodescritora brasileira: "é uma atividade de mediação linguística, uma modalidade de tradução intersemiótica, que transforma o visual em verbal [...]. Além das pessoas com deficiência visual, a áudio-descrição amplia também o entendimento de pessoas com deficiência intelectual, idosos e disléxicos".

A primeira vez que a áudio-descrição apareceu formalmente descrita, foi na tese apresentada na Universidade de São Francisco pelo norte-americano Gregory Frazier, em 1975. Uma série de estudos começaram a ser feitos e os resultados favoráveis que foram sendo comprovados nessas primeiras experiências fizeram com que a técnica se desenvolvesse em teatros, museus e cinemas na década de 80 , como por exemplo em alguns filmes do Festival de Cannes em 1989 e na televisão no Reino Unido. Rapidamente a técnica estendeu-se por alguns países da Europa. No Brasil, o primeiro filme a receber o recurso foi apenas em 2005 e seguiu sendo utilizada principalmente em filmes, teatros e em canais televisivos. Também tem-se conhecimento de algumas experiências na dança, como por exemplo, no Festival de Dança de Joinville, em que nos anos de 2014, 2015 e 2016 foi realizada a áudio-descrição da noite de gala, em especial, da apresentação de Ballet Clássico com a temática do Quebra Nozes. Anteriormente à áudio-descrição ao vivo realizada pela áudio-descritora Lívia Motta. foi disponibilizado miniaturas táteis dos bailarinos em diferentes posturas de dança, para que as pessoas com cegueira pudessem entender através do tato o que significava cada passo específico de ballet, como por exemplo o "plié",

No meio arquitetônico, urbano e de transporte no Brasil a áudio-descrição é raramente ou nunca utilizada. Os exemplos a seguir apresentarão sua potencialidade para a aplicação em sistemas de informação ao usuário do transporte coletivo e em espaços públicos urbanos.

\section{A ÁUDIO-DESCRIÇÃO COMO RECURSO PARA O TRANSPORTE COLETIVO}

$\mathrm{Na}$ ausência da visão, compreender e utilizar um sistema de transporte coletivo não é tarefa fácil, principalmente quando as informações não visuais são escassas ou inexistentes, 


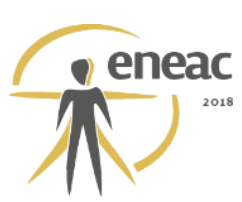

podendo tornar-se uma atividade impraticável, de forma independente, considerando que grande parte dos referenciais urbanos e de informação provida são estritamente visuais.

Pensando em tornar os sistemas de transporte público coletivo acessíveis, as informações devem ser transmitidas em mais de um canal sensorial, utilizando-se além da visão, principalmente o tato e a audição.

Os sistemas de transporte público coletivo de Londres e Viena, além de desenvolverem completos sistemas de informação ao usuário através de mais de um canal sensorial, também oferecem recursos com a descrição dos itinerários e estações do transporte coletivo, os quais são descritos a seguir.

\subsection{O Sistema de Transporte Público de Londres e a utilização da áudio-descrição}

Em 2015 Londres atingiu 8,7 milhões de habitantes, sendo 11\% da população com alguma deficiência e destes, 87 mil Londrinos com cegueira ou baixa visão. Como modos de transporte coletivo, Londres possui sistemas de trem $(7 \%$ de utilização por pessoas com deficiência), metrô (18\%), ônibus (55\%), DLR/Monorail (2\%) e VLT/Tram (2\%). Pessoas com deficiência têm o direito de viajar gratuitamente nos modos coletivos de Londres. Da mesma forma, cães de assistência (cães-guia, cães de companhia nos casos de saúde mental, cães que podem sentir quando seu proprietário está prestes a ter um ataque epiléptico, etc) também são bem vindos em todos os serviços de transporte de Londres e não pagam tarifa extra. (Transport for London - TfL, 2012).

Além das diversas formas de oferecer informação ao usuário do transporte coletivo, incluindo anúncios de áudio dentro dos veículos, painéis digitais, guias informativos em diversos formatos acessíveis e informação no site oficial da empresa responsável pelos modos públicos de transporte da cidade (Transport for London - TfL), também é oferecido um guia de áudio para orientar pessoas com deficiência visual - muito semelhante ao recurso da áudio-descrição.

O guia em áudio consiste em 38 faixas de áudio, as duas primeiras introduzem o usuário acerca das faixas disponibilizadas e as seguintes correspondem a uma linha de transporte coletivo, descrevendo as conexões, quais estações pára e não pára e os destinos. Outras faixas descrevem as estações, por ordem alfabética de cada plataforma ( $A, B, C$, etc.)

Figura 1: Guia de Áudio do TfL. Descrição da imagem: Foto da tela de parte do site do TfL em que aparecem em listagem, os áudios das estações e trajetos. Em evidência, o símbolo do TfL e a faixa de áudio selecionada sendo ouvida.
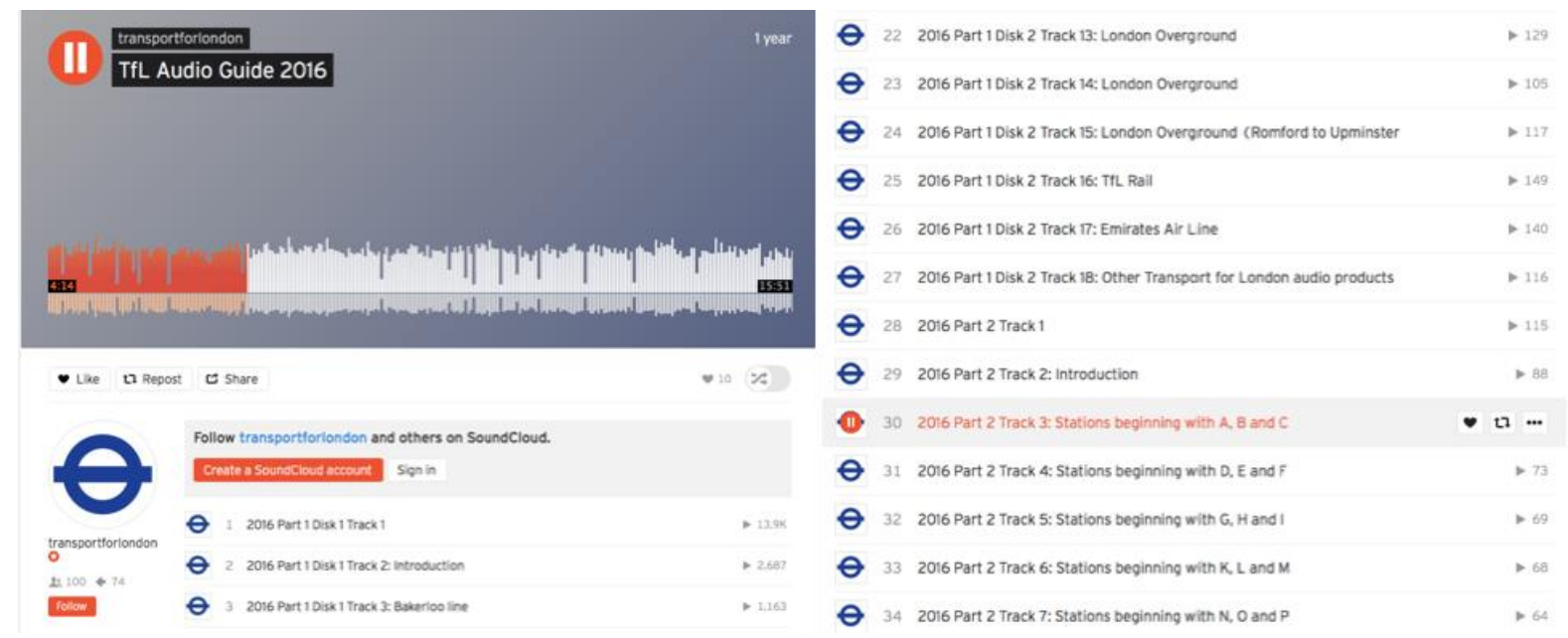

Fonte: Acervo próprio, Julho de 2017. 


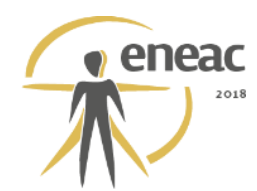

Existe um link no website do TfL em que remete para o website describe-online.com, o qual apresenta uma série de guias com descrições em texto de espaços públicos, com o objetivo de dizer que ele existe, onde se localiza, como pode ser acessado via transporte público, 0 que oferece e como pode ser utilizado. Um desses guias é o "Transport for London Services", em que cada modo de transporte é descrito, apresentando as linhas, estações e itinerários. Segue exemplo de trecho extraído do site e traduzido:

"Nosso Tube Map lista as linhas da rede de metrô de Londres em ordem alfabética. A partir daqui, você pode seguir cada linha e localizar estações de conexão. Um link em um nome de estação indica que nós desenvolvemos um guia de texto on-line para aquela estação. Nosso Transport for London Station Finder enumera as letras iniciais de todas as estações na rede em ordem alfabética. A partir daqui, você pode acessar uma lista alfabética de estações que começam com a carta selecionada. [...] Um link em uma estação com nome indica que desenvolvemos uma linha Guia de texto para aquela estação. O London Underground Map descreve as seguintes linhas: [..."]" (texto extraído do site describeonline.com, tradução literal da autora, acessado em junho de 2017).

\section{O Sistema de Transporte Público de Viena e a utilização da áudio-descrição}

Viena é a maior cidade e a capital da Áustria, com população de 1,8 milhões de pessoas, com aproximadamente $40 \%$ das viagens realizadas por transporte público. Segundo a empresa de transportes da cidade, Viena foi uma cidade pioneira na Europa e no mundo quanto as questões de acessibilidade no transporte público. Atribuem a popularidade mundial da cidade ao seu acessível e qualificado sistema de transporte, considerado um dos melhores do mundo. (EMBERGER et al., 2013)

Em 1997, cerca de 97\% das estações de metrô de Viena possuíam o sistema de orientação tátil no piso. Apenas as estações mais antigas não receberam na mesma época, pois eram protegidas pelo National Trust, e essas intervenções, como qualquer outra em edificações protegidas por sua importância (tombadas) devem passar por análise e receber autorização. Após esse processo, desde 2011 todas as estações de Viena possuem o sistema tátil.

Apesar do sistema de orientação tátil no piso ter oferecido segurança e orientação espacial, a pessoa com deficiência visual ainda dependia de alguém para the dizer sobre linhas, horários e itinerários. Assim, em novembro de 2004 foi desenvolvido pela empresa de transportes em parceria com o BBI (instituto de pessoas com deficiência visual) um sistema de orientação sonora chamado POPTIS (Pre-On-Post-Trip-Information-System), utilizando tecnologias acessíveis financeiramente, como um computador, internet, telefone celular e mp3-players.

Todas as viagens possíveis dentro da rede de transporte público de Viena foram descritas em texto e armazenadas como arquivos de áudio na base POPTIS. A base fornece as rotas recomendadas e sugere rotas de acordo com a demanda de usuários com deficiência visual. Para garantir a segurança e eficiência, todas as rotas foram testadas por professores de orientação e mobilidade do instituto $\mathrm{BBI}$ e outros especialistas.

Todas as informações disponibilizadas nas páginas do website são acessíveis aos programas de leitor de tela e cada parada é descrita detalhadamente através dos áudios disponibilizados no site e através de CD-ROM. Caso o ouvinte esteja com um smartphone, o áudio pode converter-se para texto.

O sistema de áudio ajuda as pessoas com deficiência visual no pré, durante e também no pós viagem. No pré viagem funciona como um importante guia de planejamento da rota, principalmente para iniciantes, como crianças e adolescentes com cegueira ou pessoas mais velhas que perderam a visão. Durante a viagem, o sistema auxilia no sentido de relembrar qualquer caminho ou informação, assim como refazer o trajeto com rotas alternativas. Por fim, no pós viagem, auxilia como uma recordação do trajeto realizado. As aulas de orientação e mobilidade são oferecidas pela instituição para pessoas com 


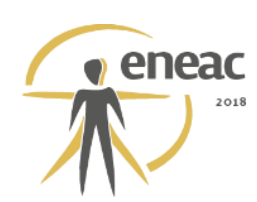

deficiência visual - BBI, que utiliza esse sistema de áudio nas aulas e testa teoricamente todas as possibilidades de rotas.

O áudio está dividido em faixas - correspondente a cada estação de metrô da cidade - e descreve os caminhos possíveis em cada estação. Cada faixa possui um conjunto de trilhas e cada trilha é subdividida em viagens: embarque, desembarque, mudança de plataformas, transferência modal - metrô para VLT ou ônibus -, assim como todos os percursos recomendados e rotas alternativas no caso de interrupções.

O sistema é comparado a um sistema modular, composto por vários módulos de texto que descrevem cada pedaço do trajeto. Ao fim, é possível construir roteiros pessoais de forma completar. Os módulos de texto incluem a descrição do edifício da estação e seus arredores, localização das entradas e saídas, andares, tipo de plataforma, recomendações sobre a escolha de caminhos, etc.

\section{A ÁUDIO-DESCRIÇÃO COMO RECURSO EM ESPAÇOS PÚBLICOS URBANOS}

Espaços turísticos e de lazer como mirantes e parques urbanos apresentam diversos locais de contemplação da paisagem, o que intimamente relaciona-se com a capacidade de enxergar. Em Joinville, Santa Catarina, o antigo Mirante da cidade foi totalmente reconstruído, agregando-se espaços de lazer, estar e práticas de exercícios, tornado-se um importante espaço público urbano - um dos poucos da cidade. Pensando em torná-lo acessível para pessoas com deficiência visual, o projeto piloto da áudio-descrição da paisagem e da estrutura foi realizado.

Reinaugurado no dia 9 de março de 2016 (aniversário da cidade), o Mirante de Joinville constitui-se em um espaço público com duas estruturas de mirante, um maior e outro menor (chamado de Janela) que se integram por uma trilha. Localiza-se no ponto mais alto do Morro da Boa Vista, região central da cidade, sendo possível visualizar a Baía Babitonga e boa parte da zona urbana, além de percorrer uma trilha em meio a Mata Atlântica. O acesso pode ser feito a pé, de bicicleta e por linhas exclusivas de ônibus. Foi projetado para ser um ponto turístico, mas tornou-se um ponto de lazer, recebendo Joinvilenses diariamente, que utilizam o caminho até o Mirante para esporte e lazer.

Incentivada pelas descobertas advindas da tese, início de 2016 a autora desenvolveu o projeto de áudio-descrição do Mirante e da Janela, sem custos financeiros, a partir dos depoimentos do autor do projeto arquitetônico, Vânio Lester Kuntze, arquiteto e urbanista, sobre a estrutura do Mirante e dos depoimentos do geógrafo Jorge Luís Araújo de Campos, acerca da paisagem. O projeto contou com o apoio da Associação Joinvilense para Integração dos Deficientes Visuais de Joinville (AJIDEVI) e da Radiodifusão de Informação da Fundação Cultural de Joinville, a qual realizou a gravação dos áudios na voz da radialista Tusi Helena de Sousa. 


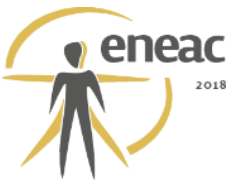

Figura 2: Inauguração do recurso da áudio-descrição no Mirante de Joinville. Descrição da imagem: Grupo de cerca de 20 pessoas com deficiência visual com a camiseta de homenagem ao aniversário de 35 anos da AJIDEVI ouvindo a áudio-descrição no topo do Mirante.

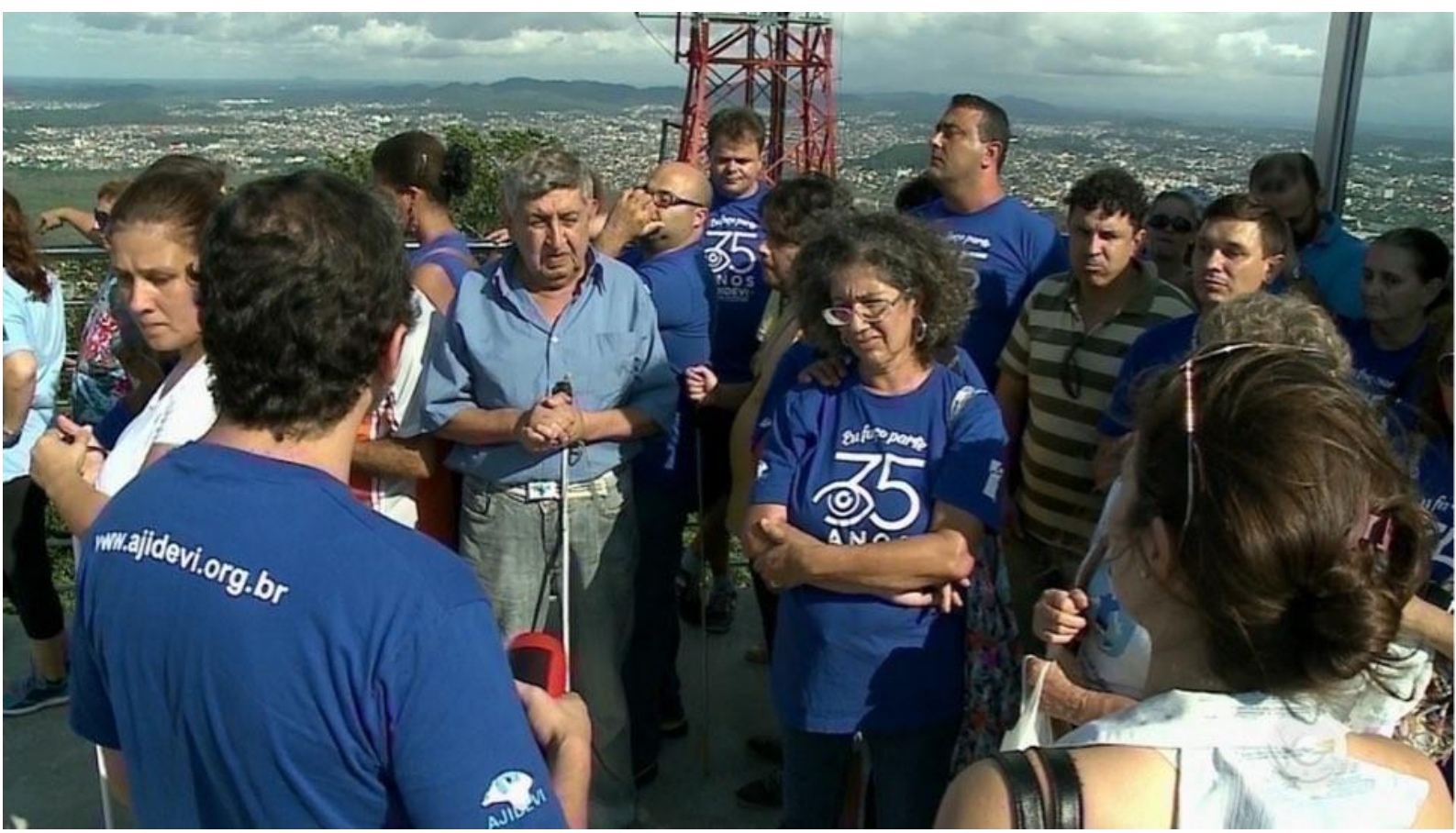

Fonte: Reportagem do jornal G1 SC em 30.04.16.

$\mathrm{Na}$ construção dos textos dos áudios, buscou-se descrever o que era visto, com informações relevantes sobre a arquitetura, a geografia e a configuração da área urbana. Percebeu-se que essas informações eram relevantes não apenas para quem não estava enxergando, mas também para visitantes da cidade ou moradores que não a conheciam tão bem. Assim, pensando-se nos turistas, o áudio foi traduzido para o alemão, inglês, francês e italiano.

Os áudios podem ser acessados de maneira online através do site da Prefeitura de Joinville (www.joinville.sc.gov.br/servicos/visitar-mirante-de-joinville/\#audio-descricoes) e serem ouvidos nos locais indicados, seja no mirante principal ou na Janela.

A áudio-descrição mostrou-se promissora e cumpriu seu papel de inclusão das pessoas com deficiência visual no mirante da cidade, conforme alguns depoimentos extraídos da reportagem do Jornal Globo - G1 Santa Catarina em 30 de abril de 2016, repercutindo intensamente na mídia local e estadual:

"O áudio que explica às pessoas com cegueira o que é avistado por quem enxerga é uma forma de mostrar que as limitações do corpo físico podem ser superadas com vontade, atitude e um bom trabalho" - Paulo Sérgio Suldóvski, com cegueira, 37 anos, presidente da AJIDEVI e servidor da Fundação Cultural.

"Dá para ter noção do que tem ao redor, na frente e ao lado e de onde está cada coisa" Jonas Oliveira, com cegueira, 29 anos. (Foto a seguir à esquerda)

"Ali é a baía Babitonga, do outro lado o bairro Costa e Silva e ali o bairro Cubatão" - José Alberto Miranda, baixa visão, 64 anos, enquanto aponta os locais para a namorada Ligia Cardoso de Carvalho, 54, que tem baixa visão e é natural de Santos. 


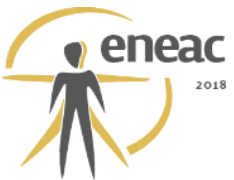

Figura 3: Duas fotos dos visitantes com deficiência visual no Mirante. Descrição das imagens: À esquerda, casal de perfil está na ponta do mirante, com guarda corpo em vidro e piso em gradil metálico, apontando para certa direção no horizonte. À direita, outro casal de perfil com as mãos apoiadas sobre o guarda corpo metálico "sentindo a paisagem", percebe-se o vendo nos cabelos encaracolados na altura dos ombros da mulher.
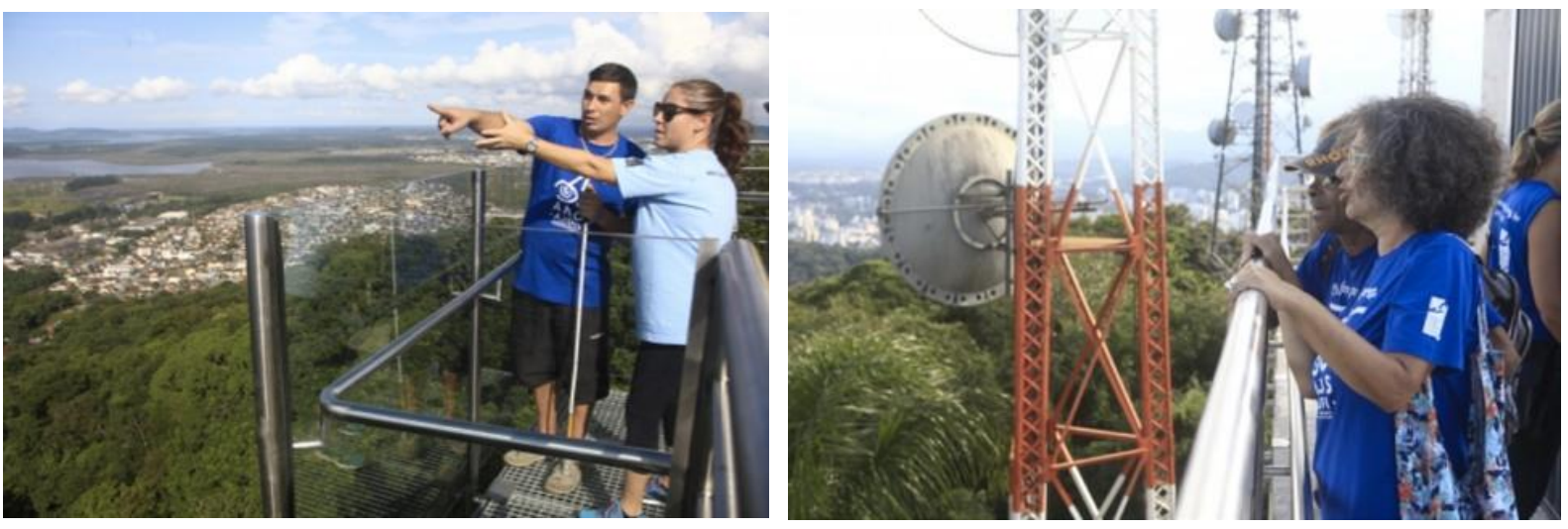

Fonte: Jornal G1 Santa Catarina. 2016.

"Quando eu enxergava eu vim aqui uma vez quando era criança, daí não entendia muito o que estava apreciando. Agora que eu não estou enxergando, mas estou ouvindo, achei bem interessante e é muito legal conhecer a cidade onde você mora, os pontos turísticos, para mim foi bem especial". Depoimento de Marilza de Goes, com cegueira, para a reportagem do Jornal local "Notícias do Dia" do dia 30 de abril de 2016.

Figura 4: Recorte do video em que Marilza de Goes faz depoimento ao Jornal G1. Descrição da imagem: Marilza de Goes aparece de perfil, com óculos escuros e microfone em sua direção, na base do recorte da tela da entrevista para o jornal televisivo, aparece seu nome.

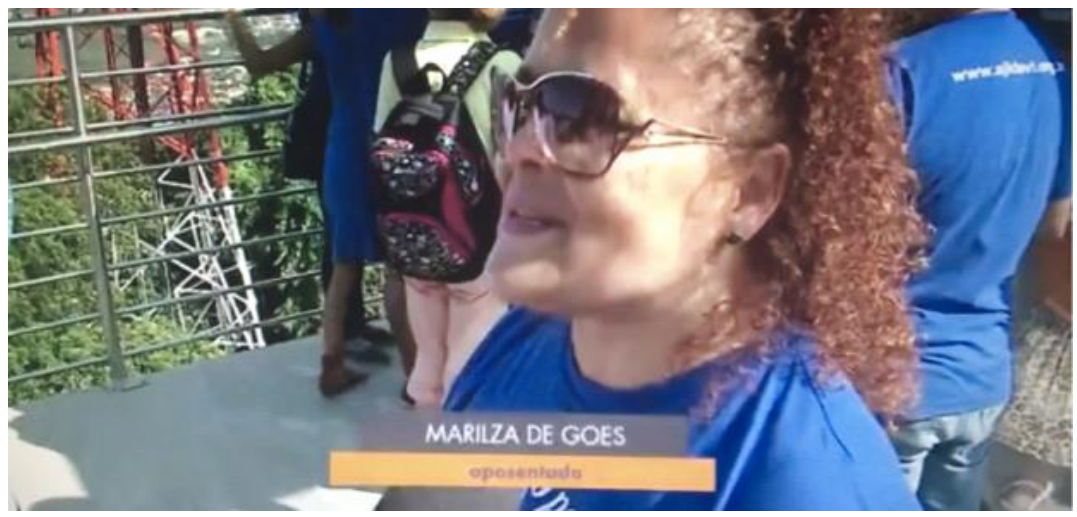

Fonte: Jornal G1 Santa Catarina. 2016.

A seguir, a transcrição dos áudios:

Áudio sobre o Mirante:

"O Mirante é uma estrutura em concreto armado com acabamento aparente, tendo 14,5 metros de altura da plataforma de observação em relação ao solo. Além da plataforma, o Mirante é composto por escadarias, elevador, e, no nível do solo, existem sanitários e salas para informações turísticas, controle e segurança. A plataforma de observação possui dois balanços, um com vista para a Baía da Babitonga (ao Leste) com, aproximadamente, 7,5 metros, e outro (para o oeste) voltado para o centro da cidade com 5,5 metros. Todo o guarda-corpo do Mirante é de aço inox e no limite do balanço voltado para a baía, tem-se 
uma estrutura metálica com grade vazada no piso para que as pessoas possam observar a paisagem abaixo e terem a sensação de que estão em um espaço flutuante. Esse mirante é o ponto mais elevado do Morro da Boa Vista, onde a paisagem é marcada, em primeiro plano, pela área urbana e, em segundo plano, pela Baía da Babitonga. A baía é uma formação geológica mais recente que a Serra do Mar e se originou quando houve a separação entre os continentes americano e africano. Era uma baía mais ampla que hoje e pelo movimento de sedimentos está ficando menor e assoreada. Essa formação estuarina, isto é, o local de encontro das águas dos rios e do mar, tem relevante importância pelo fato de ser considerada um berçário da vida marinha, com a presença de golfinhos. As aves, como o Guará também fazem parte da paisagem, com sua linda cor laranja. Nas faces leste e nordeste é possível avistar vários bairros, sendo os mais próximos os bairros Boa Vista, Comasa, Iririú, e os mais distantes, Espinheiros, Jardim Iririú e Aventureiro, este último o mais populoso da cidade. Nesses bairros há pouca verticalização, mas grande concentração populacional, o relevo é plano e há uma grande faixa de Mangue entre as áreas urbanas e o vasto corpo hídrico. Na face Sul do mirante estão os bairros centrais, que configuraram o início da formação de Joinville. Com o relevo acidentado, a urbanização aconteceu entremeada a esses morros. A face Sudeste envolve os bairros Adhemar Garcia, Fátima, Ulysses Guimarães e, mais distante, o bairro Paranaguamirim, bairros de grande concentração populacional."

Áudio sobre a Janela do Mirante:

"A Janela é um segundo mirante, mais baixo, de onde é possível visualizar a região oeste e noroeste da cidade, sem a interrupção visual das antenas e das torres de comunicação. $O$ acesso à Janela é realizado por passarela que passa sobre a rua de acesso ao mirante $(R$. Pastor Guilherme Rau), interligada à trilha ecológica elevada, que tem 600 metros de extensão, dentro da mata, no topo do morro. A trilha foi executada sobre estrutura de concreto, com deck em madeira, guarda-corpo de aço galvanizado a fogo e alguns ambientes de descanso durante o percurso. Próximo à Janela, tem-se lanchonete e sanitários de onde é possível visualizar parte da paisagem e as pessoas atravessando a passarela sobre a rua. A plataforma de observação da Janela tem altura, de aproximadamente, 15 metros e é composta por um balanço em estrutura metálica e deck de madeira, que avança cinco metros em relação à estrutura de apoio e sustentação da plataforma. Essa estrutura é constituída por dois grandes pilares, uma viga de travamento superior e outra de travamento inferior, abaixo do deck, configurando um pórtico de concreto aparente. Este pórtico emoldura a linda paisagem que possui, em primeiro plano, árvore nativa de grande porte. A vista do pôr-de-sol é deslumbrante, pondo-se na Serra do Mar, e os raios solares podem ser sentidos na pele sem obstruções. Na viga de travamento desse pórtico tem-se a inscrição "Mirante de Joinville", em letra caixa, com iluminação, para que a noite, seja visto da cidade, com luzes coloridas que podem ter coloração conforme data comemorativa, como, por exemplo, o Outubro Rosa.

A vista voltada para Noroeste, apresenta área urbana em primeiro plano e a imponente Serra do Mar ao fundo. É uma paisagem belíssima, onde há ocupação humana, com casas, prédios e a malha viária entremeada aos morros vegetados. Esses morros, que são mais baixos que a Serra do Mar, ficam floridos no final do ano devido a distribuição geográfica da Quaresmeira ocorrer até uma certa altitude e por isso não estar presente em parte da Serra do Mar. Na área urbana a verticalização destaca-se e no sentido norte-sul, observa-se os bairros: Centro, América, Bom Retiro, Santo Antônio e Costa e Silva. No horizonte é possível avistar o bairro Vila Nova. A Serra do Mar é uma formação muito antiga, com rochas plutônicas - aquelas formadas em grandes profundidades e a temperaturas muito elevadas - o que as tornaram muito resistentes aos efeitos climáticos. Parte do que foi erodido nesta Serra foi ao longo de milhares de anos, sendo carregado para as partes mais baixas do relevo, formando áreas planas, com relevos mais suavizados, o que veio a estimular a ocupação humana. Há uma diferença de tonalidade nos morros: os mais próximos possuem 


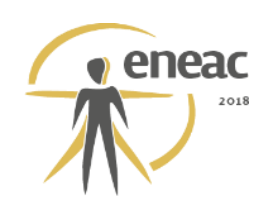

uma coloração verde escura e os mais distantes vão perdendo gradativamente essa tonalidade, ficando acinzentados."

\section{CONCLUSÕES}

O recurso da áudio-descrição é capaz de promover a inclusão de pessoas com deficiência visual nos espaços em que não se supõe serem desfrutados por pessoas com cegueira, como aconteceu no Mirante de Joinville. O projeto foi recebido com satisfação pelos usuários, que acima de tudo, mostraram-se envolvidos desde a idealização do projeto. A iniciativa mostrou-se passível de ser realizada através das prefeituras, institutos ou secretarias de planejamento urbano em parceria com radialistas e instituições de pessoas com deficiência visual, principalmente por ter sido realizada sem custos financeiros, mostrase promissora no Brasil, tendo em vista a dificuldade em implementar recursos considerados de alto custo para prefeituras.

Nos sistemas de informação ao usuário do transporte público ainda é um recurso inexplorado no país e os exemplos europeus mostraram que pode ser extremamente útil para promover o deslocamento independente de pessoas com cegueira e baixa visão, especialmente na ausência de informações locais táteis e sonoras em estações e pontos de embarque do transporte coletivo.

É importante considerar que a áudio-descrição não é útil apenas para quem não enxerga, pois ao descrever todos os aspectos do contemplado oferece ricas informações para todas as pessoas, como foi observado no projeto piloto de Joinville, em que pessoas que enxergam, mas desconhecem a cidade ou mesmo queiram entendê-la melhor, puderam também desfrutar do recurso.

Por fim, o envolvimento das pessoas com deficiência como informantes e participantes em projetos inclusivos é essencial para a efetividade e uso pleno pelos usuários foco.

\section{REFERÊNCIAS BIBLIOGRÁFICAS}

BRASIL. Convenção sobre os Direitos das Pessoas com Deficiência. 5. ed. - Brasília. Secretaria de Direitos Humanos, Secretaria Nacional de Promoção dos Direitos da Pessoa com Deficiência, 2014.

Lei Brasileira de Inclusão (Lei Federal 13.146/2015). Estatuto da Pessoa com deficiência, assegura e promove condições de igualdade, exercício dos direitos e liberdades fundamentais, visando a inclusão social e cidadania da pessoa com deficiência. Brasil. 2015.

. Lei Federal 12.587/2012. Institui a Política Nacional de Mobilidade Urbana. 2012.

GIBSON, James J. The senses considered as perceptual systems. Boston: Houghton Mifflin. 1966.

EMBERGER, Guenter; KRPATA, Roland; KÖNIG, INES; ROLLINGER Wolfgang; GRUNDNER, Maria. Public Transport For (Disabled) People - The Viena Experience. 13rd World Conference on Transport Research. WCT Rio de Janeiro. Brasil. 2013.

INSTITUTO BRASILEIRO DE GEOGRAFIA E ESTATÍSTICA (IBGE). População residente, por tipo de deficiência, segundo o sexo e os grupos de idade - Brasil. Censo demográfico 2010. Disponível em http://www.ibge.gov.br. Acessado em junho de 2015.

ORGANIZAÇÃO MUNDIAL DE SAÚDE (OMS). CID-10 Classificação Estatística Internacional de Doenças e Problemas Relacionados à Saúde. 10a rev. São Paulo. 2006.

SILVEIRA, Carolina Stolf. Acessibilidade Espacial no Transporte Público Urbano: Estudo de Caso em Joinville-SC. Dissertação de Mestrado - Programa de Pós-graduação em Arquitetura e Urbanismo 
da Universidade Federal de Santa Catarina - PósARQ, UFSC. Florianópolis, 2012. 210p.

SILVEIRA, Carolina Stolf. Orientação e Mobilidade de Pessoas com Deficiência Visual no Meio Urbano e no Transporte Coletivo: Subsídios para Sistemas de Informação ao Usuário. Tese de Doutorado - Programa de Pós-graduação em Arquitetura e Urbanismo da Universidade Federal de Santa Catarina - PósARQ, UFSC. Florianópolis, 2017. 356p.

TRANSPORT FOR LONDON. Understanding the travel needs of London's diverse communities. Mayor of London. 2012.

\section{AGRADECIMENTOS}

A pesquisadora agradece a todos os participantes com deficiência visual da pesquisa de doutorado, especialmente aos associados representados pela AJIDEVI, a qual ativamente luta pelos direitos e inclusão da pessoa com cegueira e baixa visão em Joinville e região. Agradecimentos para a Fundação IPPUJ e à radialista Tusi Helena de Sousa, através da Fundação Cultural. 